\title{
Prenatal Factors Associated with Postnatal Brain Injury in Infants with Congenital Diaphragmatic Hernia
}

\author{
(D) Radhakrishnan, (DS.L. Merhar, (D). Su, DB. Zhang, (D). Burns, DF.Y. Lim, and BD.M. Kline-Fath
}

\begin{abstract}
BACKGROUND AND PURPOSE: Approximately $60 \%$ of infants with congenital diaphragmatic hernia have evidence of brain injury on postnatal MR imaging. It is unclear whether any brain injury is present before birth. In this study, we evaluated fetal MR imaging findings of brain injury and the association of congenital diaphragmatic hernia severity with postnatal brain injury.
\end{abstract}

MATERIALS AND METHODS: Fetal MR imaging and postnatal brain MR imaging were retrospectively evaluated in 36 cases of congenital diaphragmatic hernia (from 2009 to 2014) by 2 pediatric neuroradiologists. Brain injury on postnatal MR imaging and brain injury and congenital diaphragmatic hernia severity on fetal MR imaging were recorded. Correlations between brain abnormalities on fetal and postnatal brain MR imaging were analyzed. Postnatal brain injury findings correlating with the severity of congenital diaphragmatic hernia were also assessed.

RESULTS: On fetal MR imaging, enlarged extra-axial spaces (61\%), venous sinus distention (21\%), and ventriculomegaly (6\%) were identified. No maturational delay, intracranial hemorrhage, or brain parenchymal injury was identified on fetal MR imaging. On postnatal MR imaging, $67 \%$ of infants had evidence of abnormality, commonly, enlarged extra-axial spaces (44\%). Right-sided congenital diaphragmatic hernia was associated with a greater postnatal brain injury score $(P=.05)$. Low observed-to-expected lung volume was associated with postnatal white matter injury $(P=.005)$ and a greater postnatal brain injury score $(P=.008)$. Lack of liver herniation was associated with normal postnatal brain MR imaging findings $(P=.03)$.

CONCLUSIONS: Fetal lung hypoplasia is associated with postnatal brain injury in congenital diaphragmatic hernia, suggesting that the severity of lung disease and associated treatments affect brain health as well. We found no evidence of prenatal brain parenchymal injury or maturational delay.

ABBREVIATION: $\mathrm{CDH}=$ congenital diaphragmatic hernia

A s many as $60 \%$ of infants with congenital diaphragmatic hernia $(\mathrm{CDH})$ show evidence of brain injury on MR imaging performed before discharge from the neonatal intensive care unit. $^{1-6}$ We and other investigators have shown that postnatal factors in the neonatal intensive care unit, including the use of

Received July 11, 2017; accepted after revision October 30.

From the Department of Radiology (R.R.), Riley Hospital for Children at Indiana University, Indianapolis, Indiana; Perinatal Institute (S.L.M.), Division of Neonatology, Division of Biostatistics and Epidemiology (B.Z.), Fetal Care Center (P.B., F.Y.L.), and Department of Radiology (B.M.K.-F.), Cincinnati Children's Hospital Medical Center, Cincinnati, Ohio; and Department of Mathematics (W.S.), University of Cincinnati, Cincinnati, Ohio.

Paper previously presented at: Annual Meeting of the American Society of Neuroradiology and the Foundation of the ASNR Symposium, April 22-27, 2017; Long Beach, California.

Please address correspondence to Rupa Radhakrishnan, MD, Riley Hospital for Children at Indiana University, 705 Riley Hospital Dr, Indianapolis, IN 46032; e-mail: rupa.rad@gmail.com; @RadRupa

http://dx.doi.org/10.3174/ajnr.A5500 extracorporeal membrane oxygenation, the need for inotropes, lack of oral feeding at discharge, and placement of a gastrostomy tube before hospital discharge are associated with evidence of brain injury on MR imaging. ${ }^{1,6,7}$ In addition, a large diaphragmatic defect, persistent pulmonary hypertension, and the presence of liver herniation into the chest are associated with a greater degree of brain injury postnatally. ${ }^{5}$ Despite evidence of postnatal brain injury in these infants, the presence and extent of brain injury in utero are unclear. Prior work by Danzer et $\mathrm{al}^{3}$ suggested brain maturational delay in infants with $\mathrm{CDH}$. However, this finding has not been reported in other studies, and we found no evidence of delayed maturation on postnatal brain MR imaging in our prior study of infants with $\mathrm{CDH} .{ }^{1}$

Evaluating fetal brain MRIs in this population could provide more information on the timing of injury and the possibility of in utero onset of maturational delay. Understanding the association of lung MR imaging biomarkers of $\mathrm{CDH}$ severity with brain in- 
jury could also provide valuable information when counseling parents. The goal of our study was to evaluate the presence of prenatal brain injury on fetal MR imaging in infants with $\mathrm{CDH}$ and the association of $\mathrm{CDH}$ severity assessed on fetal MR imaging with postnatal brain injury. We hypothesized that infants with $\mathrm{CDH}$ would have no evidence of prenatal brain injury and that $\mathrm{CDH}$ severity would correlate with later brain injury.

\section{MATERIALS AND METHODS \\ Patient Selection}

This retrospective review was approved by the institutional review board of Cincinnati Children's Hospital Medical Center. We identified infants with CDH born between 2009 and 2014 who had postnatal MR imaging of the brain and fetal MR imaging available for review. This cohort overlaps that in our previous study ${ }^{1}$ but is not identical. If the infant had $>1$ fetal MR imaging performed, both examinations were reviewed, but the most recent fetal MR imaging was used for statistical analysis. Fetuses with prenatally diagnosed $\mathrm{CDH}$ referred to our institution typically have undergone fetal MRIs at least once in the early third trimester to estimate lung volumes. Frequently, a second trimester fetal MR imaging is performed at the time of referral as a part of the routine diagnostic work-up to aid patient counseling.

\section{Image Review}

Fetal imaging and postnatal brain MR imaging were reviewed by 2 pediatric neuroradiologists (R.R., B.M.K.-F.) at separate time points and blinded to the postnatal brain imaging outcome. Fetal MR imaging was performed at 1.5T, on either a Signa (GE Healthcare, Milwaukee, Wisconsin) or an Ingenia (Philips Healthcare, Best, the Netherlands) system. Fetal MRIs included T2 single-shot fast-spin-echo images of the brain in 3 planes: axial, sagittal, and coronal (interleaved slices without a gap, 3-mm thickness at $<24$ weeks' gestation, and $4-\mathrm{mm}$ thickness at $>24$ weeks' gestation). At least 2 stacks in each plane were obtained to the radiologist's satisfaction. The smallest FOV possible was used. T1-weighted imaging of the fetal brain and body was performed at a slice thickness of $5 \mathrm{~mm}$. Diffusion imaging was performed intermittently before but routinely after 2012 .

Findings recorded on the fetal MR imaging were germinal matrix hemorrhage, the presence of restricted diffusion when performed, ventriculomegaly, and enlarged extra-axial spaces. Enlargement of the extra-axial spaces was determined when the distance between the inner margin of the calvaria and the frontal or parieto-occipital region was greater than the values for gestational age. ${ }^{8,9}$ Ventriculomegaly was diagnosed when the maximum width of the lateral ventricles at the level of the atrium measured $>10 \mathrm{~mm} .{ }^{10}$ The presence of maturational delay, engorged dural venous sinuses, and parenchymal signal abnormality was recorded by a senior neuroradiologist (B.M.K.-F.). Brain maturation was assessed comprehensively on T2-weighted images by comparison with a published and widely used timeline of brain development, germinal matrix involution, myelination, and cortical infolding/sulcation. ${ }^{11}$ Brain maturation was dichotomously graded as normal or delayed. Figure 1 highlights a few of the maturational changes that were assessed.
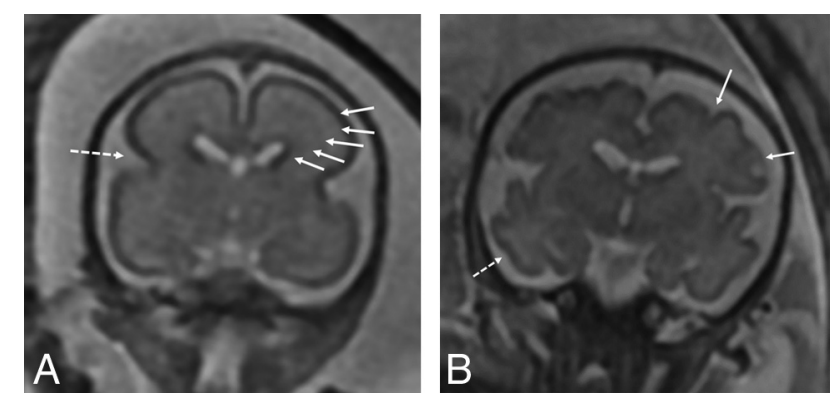

FIG 1. A, Coronal T2-weighted image of a fetus with $\mathrm{CDH}$ at 24 weeks demonstrating expected maturation with the presence of the interhemispheric and Sylvian fissure (dashed arrow), but with an otherwise smooth appearance of the frontal lobes. There is expected visualization of the migrating neurons as evidenced by alternating dark and bright bands in the cerebral parenchyma (arrows) corresponding, from inside out, to the ventricular zone/germinal matrix, periventricular fiber rich zone, intermediate zone, subplate zone, and cortical plate. B, Coronal T2-weighted image of a 32-week fetus with CDH showing age-appropriate maturation with the presence of the superior and inferior frontal sulci (arrows) and the inferior temporal sulcus (dashed arrow). The 5 layer pattern of migration is no longer present.

Postnatal imaging was performed on a 1.5T MR imaging scanner (Signa or Ingenia) or a 3T MR imaging scanner (Achieva; Philips Healthcare), or a small-bore-extremity 1.5T MR imaging scanner adapted for neonatal imaging in the neonatal intensive care unit. Postnatal imaging sequences used were T1-weighted (sagittal volume-gradient $\mathrm{T} 1$ or sagittal and axial spin-echo $\mathrm{T} 1$ ), axial and coronal T2-weighted, axial susceptibility-weighted and axial diffusion-weighted imaging, or diffusion tensor imaging in 12-15 directions. Postnatal brain MRIs were reviewed independently by 2 pediatric neuroradiologists (B.M.K.-F. and R.R.), blinded to fetal imaging and clinical factors except gestational age at time of imaging. Conflicts were resolved by consensus. A composite postnatal brain injury score was obtained to include ventriculomegaly; extra-axial space enlargement; injury to the cortex, white matter, and basal ganglia; and intraventricular, parenchymal, and cerebellar hemorrhage on a system modified by previous work by Danzer et al ${ }^{3,12}$ and Tracy et $\mathrm{al}^{5}$ and published by our group (Table 1). ${ }^{1}$ Markers of $\mathrm{CDH}$ severity, including lung volumes, side of $\mathrm{CDH}$, the presence of intrathoracic liver, and the presence of congenital heart disease (from the patient's chart) were recorded.

Lung-volume measurements were performed by specifically trained image analysis technologists in a prospective fashion using a free-standing Vitrea workstation (Vital Images, Minnetonka, Minnesota). In our institution, lung volumes are typically measured on coronal T2-weighted images. We assessed 2 commonly used measures of severity of lung hypoplasia:

Percentage Predicted Lung Volume $=$ Total Lung Volume/ Predicted Lung Volume $\times 100$, as described by Barnewolt et al, ${ }^{13}$ where Predicted Lung Volume $=$ Total Thoracic Volume - Mediastinal Volume.

Observed-To-Expected Lung Volume $=$ Total Lung Volume/ Expected Lung Volume, where Expected Lung Volume = $0.0033 \times(\text { Gestational Age in Weeks })^{2.86}$ based on the formula by Rypens et al. ${ }^{14}$

The size of the diaphragmatic defect was assessed on the basis of surgical notes, classified according to the Congenital Diaphragmatic Hernia Study Group classification from A to D, with A 
Table 1: Postnatal brain injury scoring system ${ }^{\mathrm{a}}$

\begin{tabular}{|c|c|c|c|c|c|}
\hline \multirow[b]{2}{*}{ MRI Finding } & \multicolumn{5}{|c|}{ MRI Score } \\
\hline & 0 & 1 & 2 & 3 & 4 \\
\hline Ventriculomegaly & $<10 \mathrm{~mm}$ & $10-15 \mathrm{~mm}$ & $>15 \mathrm{~mm}$ & Obstructive & \\
\hline Extra-axial spaces & $<5 \mathrm{~mm}$ & $5-10 \mathrm{~mm}$ & $>10 \mathrm{~mm}$ & & \\
\hline Intraventricular hemorrhage & None & Grade 1 & Grade 2 & Grade 3 & Grade 4 \\
\hline $\begin{array}{l}\text { Parenchymal hemorrhage (not grade } 4 \\
\text { intraventricular hemorrhage) }\end{array}$ & Absent & Present & & & \\
\hline Cerebellar hemorrhage & None & $<3$ foci, $<5-\mathrm{mm}$ size & $>3$ foci or $>5-\mathrm{mm}$ size & & \\
\hline White matter injury & None & $<3$ foci, unilateral & $>3$ foci or bilateral & Multiregional & \\
\hline Cortical injury & None & Single & Multiple & Extensive & \\
\hline Basal ganglia injury & None & Single & Multiple & Extensive & \\
\hline
\end{tabular}

a Postnatal brain injury graded on a published scale.

being a small defect and D reflecting diaphragmatic agenesis. ${ }^{15}$ For our analysis, we dichotomized the diaphragmatic defect size, with $\mathrm{A}$ or $\mathrm{B}$ being small and $\mathrm{C}$ or $\mathrm{D}$ being a large defect.

\section{Statistical Analysis}

Descriptive statistics were performed to describe the characteristics of the prenatal and postnatal variables. Total injury scores were compared among different levels of categoric variables using 1-way ANOVA. The relationship among categoric variables was assessed by a $\chi^{2}$ test or Fisher exact test. The Pearson correlation was used to evaluate the correlation among continuous variables. Associations between prenatal antecedents, such as the presence of brain injury and the severity of diaphragmatic hernia, and postnatal brain injury findings were analyzed using multivariate linear regression models. The association between any brain injury and the risk factors was assessed using logistic regression models. All analyses were performed with SAS, Version 9.4 (SAS Institute, Cary, North Carolina). $P<0.05$ was considered statistically significant.

\section{RESULTS}

Fifty-six infants with $\mathrm{CDH}$ had postnatal imaging, of whom 36 infants (17 girls) had fetal MRIs and were included in the study. Sixty-two fetal MRIs had been performed on these 36 infants. Twenty-six infants had 2 fetal MRIs, and 10 had 1 fetal MRI. Fetal MRI was performed between 20 and 36 weeks' postmenstrual age. Thirty-five infants had at least 1 fetal MRI in the third trimester, and only 1 infant had a single fetal MRI in the second trimester.

On fetal MR imaging, enlarged extra-axial spaces were the most common brain finding, seen in 22/36 MRIs (Fig 2). Other less common findings were the presence of venous sinus distention (Fig 3) and ventriculomegaly (Table 2). Ventriculomegaly was mild, seen only on the early MR imaging in 2 infants and resolved on the subsequent third trimester MR imaging. There were no cases of maturational delay, intracranial hemorrhage, or brain parenchymal injury identified on fetal MR imaging. Findings related to $\mathrm{CDH}$ severity are listed in Table 3.

On postnatal MR imaging, 24/36 infants had findings of brain injury (Table 4 ). The average brain injury score was $1.8 \pm 1.8$. The most common postnatal MR imaging finding was enlarged extraaxial spaces. Postnatal enlargement of extra-axial spaces was associated with a larger defect size $(P=.003)$, right diaphragmatic hernia $(P=.026)$, lower percentage predicted lung volume $(P=$ $.02)$, and enlarged extra-axial spaces on the last fetal MR imaging $(P=.02)$.
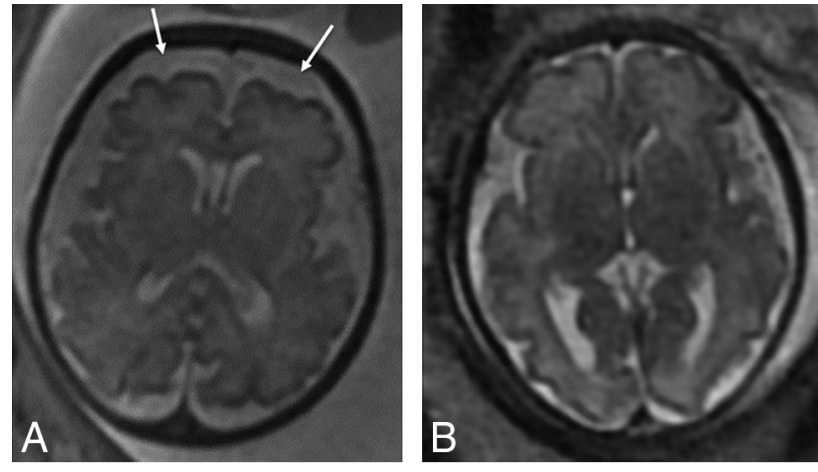

FIG 2. Axial T2-weighted images of two 32-week fetuses with $C D H$ with enlarged extra-axial spaces as marked by arrows $(A)$ and normal extra-axial spaces $(B)$.
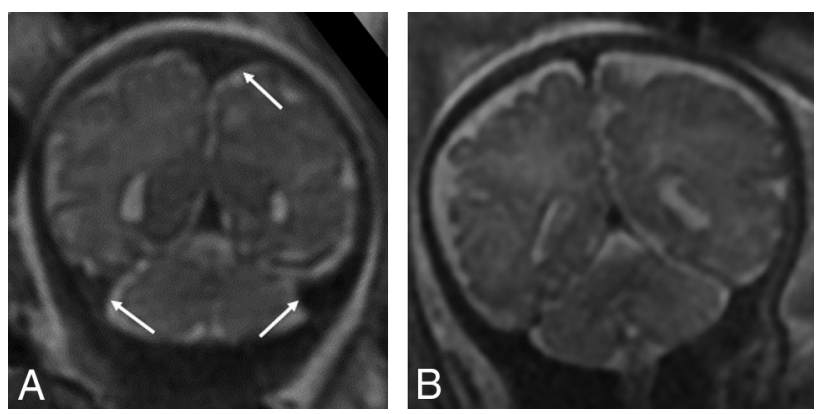

FIG 3. Coronal T2-weighted images of a 34-week fetus with $\mathrm{CDH}(A)$ with engorged dural venous sinuses (arrows) and a comparison 34week fetus without $\mathrm{CDH}(B)$ without dural venous sinus engorgement.

\section{Table 2: Brain injury on fetal MRI}

\begin{tabular}{lc}
\hline \multicolumn{1}{c}{ Pattern of Injury ${ }^{\text {a }}$} & No. (\%) \\
\hline Enlarged extra-axial spaces & $22(61)$ \\
Venous sinus distention & $9(21)$ \\
Ventriculomegaly & $2(6)$ \\
Germinal matrix hemorrhage & None \\
Diffusion abnormalities & None \\
Parenchymal abnormalities & None \\
Delayed sulcation & None \\
\hline
\end{tabular}

$a_{n}=36$.

Right-sided $\mathrm{CDH}$ was significantly associated with postnatal ventriculomegaly (OR,7.67; 95\% CI, 1.36-43.14; $P=.02)$ and a greater postnatal brain injury score (mean, $2.5 \pm 2$ for right-sided $\mathrm{CDH}$ versus mean, $1.54 \pm 1.73$ for left $\mathrm{CDH}, P=.05)$. Low observed-to-expected lung volume was associated with postnatal white matter injury $(P=.005)$. Lack of liver herniation was asso- 
ciated with normal postnatal brain MR imaging findings $(P=$ $.03)$.

The postnatal brain injury score was almost moderately correlated (Pearson correlation coefficient $=-0.44, P=.008$ ) with fetal observed-to-expected lung volume (Fig 4).

\section{DISCUSSION}

Our data show that prenatal imaging assessment of the severity of congenital diaphragmatic hernia is associated with brain injury on postnatal predischarge MR imaging. We also show that most fetuses had enlarged extra-axial spaces on the MR imaging performed in late gestation. The cause of this abnormality is unclear, and none of the factors of the severity of congenital diaphragmatic hernia (side, size of defect, percentage predicted lung volume, observed-to-expected fetal lung volume) correlated with this

Table 3: Findings related to $\mathrm{CDH}$ severity on fetal MRI

\begin{tabular}{|c|c|}
\hline CDH Severity Markers $^{\mathrm{a}}$ & \\
\hline $\begin{array}{l}\text { Mean (range) of percentage predicted } \\
\text { lung volume }\end{array}$ & $23.4 \%(11.7 \%-64 \%)$ \\
\hline $\begin{array}{l}\text { Mean (range) of observed-to-expected } \\
\text { lung volume (o/e TLV) }\end{array}$ & $0.44(0.19-0.69)$ \\
\hline $\begin{array}{l}\text { No. of infants with right-sided } \\
\text { diaphragmatic hernia }\end{array}$ & $10(28 \%)$ \\
\hline $\begin{array}{l}\text { No. of infants with liver herniation into } \\
\text { chest }\end{array}$ & $19(53 \%)$ \\
\hline $\begin{array}{l}\text { No. of infants with large diaphragmatic } \\
\text { defect }\end{array}$ & $21(58 \%)$ \\
\hline
\end{tabular}

Note:- o/e TLV indicates observed to expected total lung volume.

${ }^{a} n=36$.

Table 4: Findings of brain injury on postnatal MRI

\begin{tabular}{lc}
\hline \multicolumn{1}{c}{ Pattern of Injury ${ }^{\text {a }}$} & No. (\%) \\
\hline Enlarged extra-axial spaces & $16(44)$ \\
Intraventricular hemorrhage & $7(19)$ \\
Ventriculomegaly & $6(17)$ \\
Cerebellar hemorrhage & $6(17)$ \\
White matter injury & $6(17)$ \\
Parenchymal hemorrhage & $2(6)$ \\
\hline a
\end{tabular}

${ }^{a} n=36$.

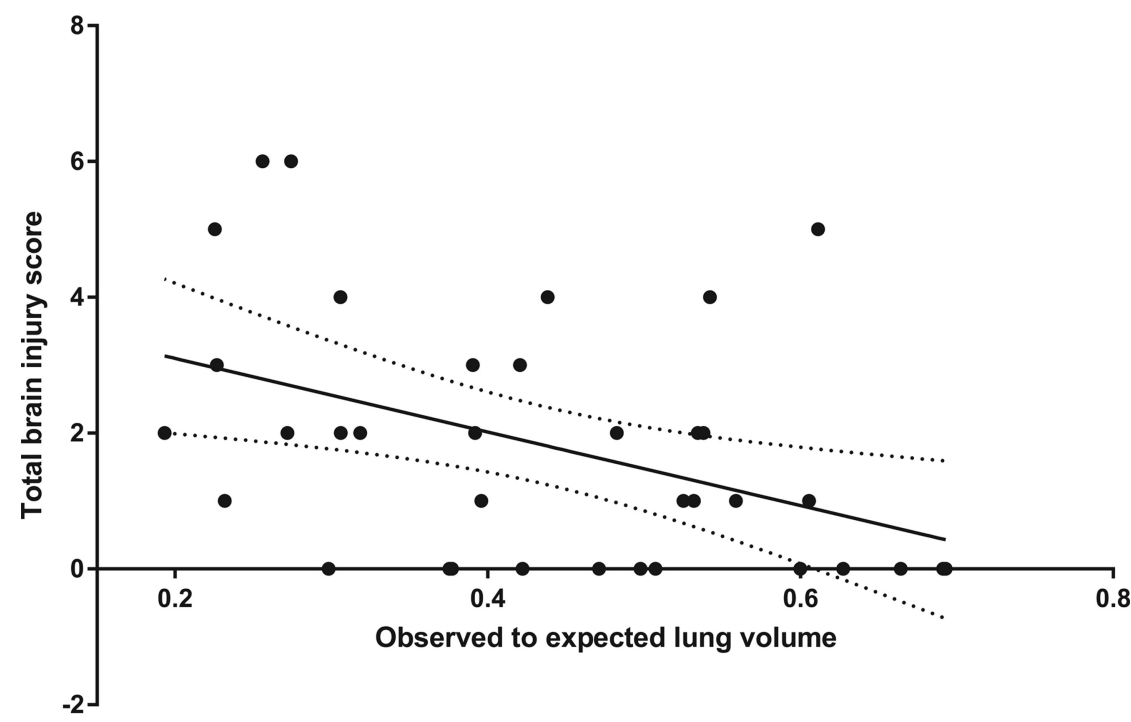

FIG 4. Postnatal brain injury score correlated negatively with observed to expected total lung volume on the latest fetal MR imaging (Pearson correlation coefficient $=-0.44, P=.008$ ). finding. It is possible that the presence of some degree of venous hypertension due to mass effect by the congenital diaphragmatic hernia and resultant alterations in CSF dynamics might play a role in the presence of this finding prenatally. In a study by Tracy et $\mathrm{al},{ }^{5}$ in fetuses with $\mathrm{CDH}$, there were only 2 fetuses with enlarged extra-axial spaces, one of which had normalized in the third trimester. It is surprising that the incidence of enlarged extra-axial spaces in their study differed substantially from ours, and this may relate to methods of measurement of extra-axial space enlargement. As mentioned in the "Materials and Methods" section, we based our measurements on previously published criteria by Watanabe et al. ${ }^{9}$ The same measurement was also used in another study of fetuses with congenital heart disease, in which the authors found enlarged extra-axial spaces and mild ventriculomegaly as the most common abnormality, seen in $70 \% .{ }^{8}$ The enlargement of the extra-axial spaces in the congenital heart disease study was attributed to a combination of delayed maturation and altered CSF dynamics. ${ }^{8}$ However, in our cohort of fetuses with $\mathrm{CDH}$, we did not find any sulcation delay, and we propose some degree of venous sinus hypertension due to intrathoracic mass effect affecting CSF resorption as a cause of the enlarged extraaxial spaces.

Another finding that would support central venous compression in the chest from the diaphragmatic hernia would be the prominent dural sinuses, which we identified in 9 fetuses. We realize that while there are no specific measures of fetal dural venous sinus distention, this specific finding was graded in a blinded fashion by an expert fetal neuroimager (B.M.K.-F.) with 12 years' experience. In spite of lack of strict objective criteria, dural venous sinus engorgement has also been suggested by other fetal imaging colleagues in informal discussion. Most interesting, the presence of dural venous sinus distention did not correlate with postnatal evidence of brain injury; therefore, the clinical implication of this finding is unclear. It is possible that we failed to demonstrate significant correlations with postnatal brain injury due to the small sample size. Future investigations that would help to better understand venous flow and CSF dynamics could be directed at measurement of central venous pressures on echocardiograms in fetuses and infants with $\mathrm{CDH}$.

The transient mild ventriculomegaly that we identified in 2 fetuses in the third trimester is of uncertain etiology. Tracy et $\mathrm{al}^{5}$ did not identify ventriculomegaly in their cohort of fetuses with $\mathrm{CDH}$. This may, therefore, be an incidental finding.

We identified significant relationships of the severity of lung hypoplasia with postnatal brain injury. The severity of lung hypoplasia is known to be associated with postnatal pulmonary artery hypertension, ${ }^{16}$ greater use of extracorporeal membrane oxygenation, and greater neonatal mortality. ${ }^{17}$ Spaggiari et $\mathrm{al}^{16}$ specifically found that observed to expected total lung volume obtained by MR imaging and intrathoracic liver were associated with pul- 
monary artery hypertension, but not right $\mathrm{CDH} .{ }^{16}$ This information would aid in prenatal counseling because the risk of brain injury may also be increased in severe lung hypoplasia.

Other important information gained from this study is the relative timing of brain injury in infants with $\mathrm{CDH}$. Lack of brain parenchymal injury prenatally and evidence of brain parenchymal injury after a $\mathrm{CDH}$ operation suggest that brain injury likely occurs after birth in these infants as they transition out of fetal circulation. Furthermore, in a series of infants with CDH, Tracy et $\mathrm{al}^{5}$ showed that the findings of the first postnatal head sonography before surgical correction of $\mathrm{CDH}$ were usually normal; this result would indicate that most brain parenchymal injury occurred later in the neonatal period, possibly during the time in the neonatal intensive care unit or the operation. In addition, the use of extracorporeal membrane oxygenation may also be a postnatal contributing factor for brain injury as we identified in our previous neonatal study. This timeline for the occurrence of brain injury in $\mathrm{CDH}$ could aid in developing appropriate guidelines for neuroprotective neonatal and surgical care at the time of greatest vulnerability to injury.

Due to the retrospective nature of the study, we were not able to control for other factors unrelated to $\mathrm{CDH}$ that might have played a role in the fetal imaging findings in these infants. Detailed maternal history was not always available for review. The size of the fetal brain is much smaller than the neonatal brain, and subtle abnormalities may not be perceptible at this stage with routine anatomic MR imaging. Diffusion tensor imaging may provide additional details on microstructural brain injury in these fetuses with $\mathrm{CDH}$. Due to our small sample size, we may have failed to demonstrate other significant associations between the severity of $\mathrm{CDH}$ and prenatal and postnatal brain injury. However, we attempted to reduce bias and improve confidence in our findings by blinded review of fetal and postnatal brain MR imaging findings, as well as CDH severity. Our data show that postnatal brain injury is related to the severity of lung hypoplasia in $\mathrm{CDH}$ identified prenatally. The timing of major parenchymal brain injury is likely perinatal or neonatal, and not prenatal.

\section{CONCLUSIONS}

We provided a detailed assessment of the association of prenatal brain MR imaging findings and $\mathrm{CDH}$ severity with postnatal MR imaging evidence of brain injury. Enlarged extra-axial spaces in the third trimester were found to be the most common abnormality prenatally. Postnatal brain injury was influenced by a measure of prenatal pulmonary hypoplasia (o/e TLV). Absence of maturational delay or major parenchymal injury on fetal MR imaging suggests that these forms of brain injury are likely related to perinatal/early neonatal events rather than in utero injury.

Disclosures: Stephanie Merhar-UNRELATED: Grants/Grants Pending: KL2, Comments: 5KL2TR001426-03, KL2 award for neuroimaging and motor outcomes, Principal Investigator, Merhar; Travel/Accommodations/Meeting Expenses Unrelated to Activities Listed: Pediatrix meeting, Orlando Florida, February 2017. Beth KlineFath-UNRELATED: Payment for Lectures Including Service on Speakers Bureaus: Applied Radiology Webinar, Comments: $\$ 1500$.

\section{REFERENCES}

1. Radhakrishnan R, Merhar S, Meinzen-Derr J, et al. Correlation of MRI brain injury findings with neonatal clinical factors in infants with congenital diaphragmatic hernia. AJNR Am J Neuroradiol 2016;37:1745-51 CrossRef Medline

2. Hunt RW, Kean MJ, Stewart MJ, et al. Patterns of cerebral injury in a series of infants with congenital diaphragmatic hernia utilizing magnetic resonance imaging. J Pediatr Surg 2004;39:31-36 CrossRef Medline

3. Danzer E, Zarnow D, Gerdes M, et al. Abnormal brain development and maturation on magnetic resonance imaging in survivors of severe congenital diaphragmatic hernia. J Pediatr Surg 2012;47: 453-61 CrossRef Medline

4. Ahmad A, Gangitano E, Odell RM, et al. Survival, intracranial lesions, and neurodevelopmental outcome in infants with congenital diaphragmatic hernia treated with extracorporeal membrane oxygenation. J Perinatol 1999;19(6 Pt 1):436-40 CrossRef Medline

5. Tracy S, Estroff J, Valim C, et al. Abnormal neuroimaging and neurodevelopmental findings in a cohort of antenatally diagnosed congenital diaphragmatic hernia survivors. J Pediatr Surg 2010;45: 958-65 CrossRef Medline

6. Danzer E, Hedrick HL. Neurodevelopmental and neurofunctional outcomes in children with congenital diaphragmatic hernia. Early Hum Dev 2011;87:625-32 CrossRef Medline

7. Danzer E, Gerdes M, Bernbaum J, et al. Neurodevelopmental outcome of infants with congenital diaphragmatic hernia prospectively enrolled in an interdisciplinary follow-up program. J Pediatr Surg 2010;45:1759-66 CrossRef Medline

8. Brossard-Racine M, du Plessis AJ, Vezina G, et al. Prevalence and spectrum of in utero structural brain abnormalities in fetuses with complex congenital heart disease. AJNR Am J Neuroradiol 2014;35: 1593-99 CrossRef Medline

9. Watanabe Y, Abe S, Takagi K, et al. Evolution of subarachnoid space in normal fetuses using magnetic resonance imaging. Prenat Diagn 2005;25:1217-22 CrossRef Medline

10. Wax JR, Bookman L, Cartin A, et al. Mild fetal cerebral ventriculomegaly: diagnosis, clinical associations, and outcomes. Obstet Gynecol Surv 2003;58:407-14 Medline

11. Kline-Fath BM. Fetal magnetic resonance imaging: normal brain imaging. In: Kline-Fath BM, Bulas DI, Bahado-Singh R, eds. Fundamental and Advanced Fetal Imaging: Ultrasound and MRI. Philadelphia: Wolters Kluwer; 2015

12. Danzer E, Gerdes M, D’Agostino JA, et al. Longitudinal neurodevelopmental and neuromotor outcome in congenital diaphragmatic hernia patients in the first 3 years of life. J Perinatol 2013;33:893-98 CrossRef Medline

13. Barnewolt CE, Kunisaki SM, Fauza DO, et al. Percent predicted lung volumes as measured on fetal magnetic resonance imaging: a useful biometric parameter for risk stratification in congenital diaphragmatic hernia. J Pediatr Surg 2007;42:193-97 CrossRef Medline

14. Rypens F, Metens T, Rocourt N, et al. Fetal lung volume: estimation at MR imaging-initial results. Radiology 2001;219:236-41 CrossRef Medline

15. Tsao K, Lally KP. The Congenital Diaphragmatic Hernia Study Group: a voluntary international registry. Semin Pediatr Surg 2008; 17:90-97 CrossRef Medline

16. Spaggiari E, Stirnemann JJ, Sonigo P, et al. Prenatal prediction of pulmonary arterial hypertension in congenital diaphragmatic hernia. Ultrasound Obstet Gynecol 2015;45:572-77 CrossRef Medline

17. Büsing KA, Kilian AK, Schaible $\mathrm{T}$, et al. MR relative fetal lung volume in congenital diaphragmatic hernia: survival and need for extracorporeal membrane oxygenation. Radiology 2008;248: 240-46 CrossRef Medline 